\title{
Diversity Dimensions of Freshwater Fish Species around the World
}

\author{
Carlos Granado-Lorencio1, Cástor Guisande², Patricia Pelayo-Villamil ${ }^{3}$, \\ Ana Manjarrés-Hernández ${ }^{4}$, Emilio García-Roselló ${ }^{\text {, Juergen Heine }}{ }^{5}$, Elisa Pérez-Costas ${ }^{2}$, \\ Luis González-Vilas², Jacinto González-Dacosta ${ }^{5}$, Jorge M. Lobo ${ }^{6 *}$
}

\author{
${ }^{1}$ Departamento de Biología Vegetal y Ecología, Facultad de Biología, Universidad de Sevilla, Seville, Spain \\ ${ }^{2}$ Facultad de Ciencias del Mar, Universidad de Vigo, Campus Lagoas-Marcosende, Vigo, Spain \\ ${ }^{3}$ Grupo de Ictiología, Universidad de Antioquia, Medellín, Colombia \\ ${ }_{4}^{4}$ Instituto Amazónico de Investigaciones (IMANI), Universidad Nacional de Colombia, Leticia, Colombia \\ ${ }^{5}$ Department of Computer Science, Universidad de Vigo, Campus Lagoas-Marcosende, Vigo, Spain \\ ${ }^{6}$ Departamento de Biogeografía y Cambio Global, Museo Nacional de Ciencias Naturales (CSIC), Madrid, Spain \\ Email: *jorge.lobo@mncn.csic.es
}

\begin{abstract}
How to cite this paper: Granado-Lorencio, C., Guisande, C., Pelayo-Villamil, P., Manjarrés-Hernández, A., García-Roselló, E., Heine, J., Pérez-Costas, E., González-Vilas, L., González-Dacosta, J. and Lobo, J.M. (2021) Diversity Dimensions of Freshwater Fish Species around the World. Journal of Geographic Information System, 13, 1-18. https://doi.org/10.4236/jgis.2021.131001
\end{abstract}

Received: November 23, 2020

Accepted: January 1, 2021

Published: January 4, 2021

Copyright $\odot 2021$ by author(s) and Scientific Research Publishing Inc. This work is licensed under the Creative Commons Attribution International License (CC BY 4.0).

http://creativecommons.org/licenses/by/4.0/ (c) (i) Open Access

\begin{abstract}
The quality and coverage of the available taxonomical and geographical information and the recognition that diversity is multi-faceted are two main factors that hinder to understand the spatial and temporal variations of biodiversity. In this study, we aim to quantify the global distribution of five diversity components used to assess freshwater fish diversity in river basins around the world. The multidimensional character of these diversity components was estimated and the so obtained diversity dimensions mapped. This was done taking into account those well-surveyed basins discriminated by considering collector's curves, and additionally by controlling for the effect of survey effort on all considered diversity components. A total of 1,472,109 occurrence records were analysed, corresponding to 17,292 species of freshwater fishes. Five diversity components were considered: functional richness, species richness, taxonomic diversity, and two rarity measures. Well-surveyed river basins were discriminated using accumulation curves. The effects of survey biases and knowledge gaps were minimized by determining the relationship of each component with the completeness values calculated for each river basin. The geographical pattern derived from raw data is skewed by the unequal knowledge available, and all diversity components were positively correlated with completeness values. The first dimension described the association between species richness and functional diversity. The second dimension represented rarity and taxonomic diversity. The congruence between species richness and functional diversity suggests that ecosystem functions
\end{abstract}


increase with the number of fish species present in river basins and that a decrease in species richness may involve a loss of functionality. The levels of rarity and taxonomic diversity of many species-poor basins found in arid and cold regions suggest that the distinctiveness of their freshwater fishes is primarily a consequence of how isolated these basins are.

\section{Keywords}

Diversity Components, Functional Diversity, Species Richness, Rarity, Taxonomic Diversity

\section{Introduction}

One of the main goals of the Ecology and Biogeography is to understand the spatial and temporal variations that underlie biodiversity [1] [2]. However, two factors complicate this mission: 1) All the variables used to measure diversity (diversity components) depend fundamentally on the quality and coverage of the available taxonomical and geographical information [3] [4]; 2) Diversity is a multi-faceted measure [5] [6] [7]. The evolutionary history, phenetic variability and ecological functions of different species, among other dimensions of diversity, interact and covary according to a syndromic pattern. The multidimensional nature of biodiversity means that many of the commonly recognized diversity variables are associated and that some variables are better than others in explaining ecosystem functions [8] [9] [10].

Large-scale distributional patterns in freshwater fishes have been assessed according to species richness [11], endemicity [12] [13] and, more recently, beta diversity [14] [15], and functional diversity [16]. These studies have primarily focused on estimating the probable causal processes behind fish diversity [17] [18]. Freshwater fish research has been influenced by the multidimensional approach towards understanding biodiversity [19] [20]. Functional diversity measurements have begun to be incorporated into basic and applied studies [21] [22]. Ecosystem functioning is linked with the functional diversity of the species within ecosystems [23]; therefore selecting the right species traits and metrics to estimate functional diversity has become a priority. A recent review [24] demonstrated that a plurality of functional diversity studies have been of plants $(31 \%)$, while a far smaller proportion of studies have been of fishes (8\%). Most of the latter studies focus on marine species. There have been few functional studies of freshwater fish [25]-[33]. Most large-scale functional diversity studies of freshwater fishes have been based on ecomorphological traits (e.g. [34]) and focus on the relationships between taxonomic and functional diversity in coral fishes [35] [36].

In the present study, we use comprehensive world information about the taxonomy and distribution of freshwater fishes to examine the multidimensional character of several diversity components. We made a special effort to estimate 
the functional diversity by delineating different trait states for over 16,000 species. Surveys carried out in the different world river basins may seriously affect diversity measurements [37]. Therefore, diversity dimensions were estimated in well-surveyed basins that had been discriminated using collector's curves. Additionally, the effect of survey effort on all considered diversity components was controlled. The aim of these analyses is to describe the geographic distribution of the main diversity dimensions observed in freshwater fishes globally and to determine the impact of each diversity component on this distribution.

\section{Methods}

\subsection{Occurrence Records and River Basins}

The data set of geographical records for freshwater fishes reported by Pelayo-Villamil et al. [38] was updated to reflect changes in taxonomy and to include the novel species described as of January 2020. Data sources include GBIF, web pages, museum collections, and journal articles [38]. Records were downloaded and filtered using the ModestR software package [39] [40] [41] [42]. GBIF records were filtered as follows: 1) records with the same latitude and longitude were excluded, 2) records with zero latitude or longitude were excluded, and 3) occurrences in habitats other than those corresponding to terrestrial freshwater ecosystems were eliminated [see 41 for details]. As of January 2020, 17,292 species of freshwater fishes were recognized by taxonomists as valid. Information about these species can be found on the website IPez1.4 (http://www.ipez.es, [43]). Of these, 17,148 (99.2\% of the total) had associated geographical information. In total, 11,472,109 occurrence records were analysed.

The geospatial data for river basins were downloaded from the WaterBase project website (http://www.waterbase.org). This data was processed using ModestR. WaterBase global river basin data were downloaded from the drainage basin data set distributed through HYDRO1k, a hydrological database developed by the EROS Data Center of the U.S. Geological Survey (USGS). This database included a collection of global geo-referenced layers that had a $1 \mathrm{~km}$ resolution. These layers had been derived from GTOPO30, a 30 arc-second digital elevation model (DEM) of the World. Using the World Geodetic System 1984 standard (WGS84), the drainage basins data were assigned latitude/longitude geographical coordinates. In order to generate the ESRI Shape files available via the WaterBase website, vertices were smoothed out by applying a 500-meter threshold. The river basin dataset was originally obtained by combining flow accumulation and flow direction layers. These layers were derived from the DEM, which had been hydrologically corrected according to GTOPO30 dataset. The basins were organized using procedure of Pfafstetter [44], which had been adapted for use with the HYDRO1k dataset [45]. River basins were divided into six levels. Each sub-basin was assigned a unique Pfafstetter code, (i.e., a six-digit code with information regarding the interconnectedness of the basins). The second level of 
each river basin [46] as used as the spatial unit for estimating diversity measurements $(n=440)$. This is because the second level was the geographical extent that best illustrated the effects of environmental parameters on the distribution of freshwater fish species [47].

\subsection{Biodiversity Metrics and Biological Traits}

Using the DER function of the EcoIndR package [48] [49] of the R software package [50], five diversity components representing different biodiversity metrics were estimated for each river basin: species richness (SR), geographic rarity (GR), rarity index (LR), taxonomic diversity (TD), and functional richness (FRic). GR reflected the average rarity of all species present in each river basin and was calculated as the inverse of the relative frequency of occupied basins [51]. LR weight the species according to their rarity (see [52] [53]). TD was used to determine the taxonomic hierarchical Linnaean level of the species observed in each river basin [54]. The FRic was defined as the volume of the functional space occupied by the species [55].

We modified the classification system described by Buisson et al. [56] in order to apply it to the functional description of freshwater fish species. Six traits were analysed. These traits represented three basic biological functions: Food acquisition traits, life habitat, and locomotion traits. Food acquisition traits were: 1) feeding habitat (pelagic, benthopelagic and benthivorous); and 2) trophic guild (primary consumer, secondary consumer, top-predator, omnivorous and detritivorous). Life habitat was defined as either pelagic, benthopelagic, or demersal. Locomotion traits were: 1 ) body length (in $\mathrm{cm}$ : small < 15, medium 15 - 50, large 50 - 150 and extra-large $>150$ ), 2) rheophily (rheophilic, limnophilic and eurytopic) and 3) migration type (potamodromous, anadromous, catadromous, amphidromous, oceanodromous and no migration). When not available through FishBase, this information was collect either from https://www.fishbase.org/ or from source articles.

It was not possible to include reproduction traits such as life span, parental care or reproduction habitat, because it was too difficult to assign these functional traits to over 16,000 species.

\subsection{Well-Surveyed River Basins and Data Treatment}

According to Pelayo-Villamil [37], 71\% of world countries had inventories of freshwater fish species that were of poor quality. Differences in the quality of inventories could be observed between countries. Furthermore, even those countries with relatively accurate and reliable national inventories had provincial and regional inventories that varied highly in completeness [37]. Therefore, whenever the available raw occurrences of the species had been used in the past, species richness in some river basins had doubtlessly been underestimated. In order to prevent this bias, potentially well-surveyed river basins (WSB) were discriminated using the RWizard [57] application KnowBR [58] (www.ipez.es/RWizard). KnowBR was also available as an R package on CRAN [59]. KnowBr was used to 
build species accumulation curves from database records. As a surrogate for the survey effort carried out in each river basin, these curves described the relationship between the accumulated number of species and the increasing number of database records taken. WSBs were therefore defined as those basins which simultaneously had a final accumulation curve slope of $\leq 0.02$ (two new species added every 100 records), a completeness value of $\geq 90 \%$ (the percentage of species predicted by the accumulation function that were also observed), and a ratio of number of records to number of observed species of $\geq 15$. Fifty-two world river basins fulfilled these requirements (12.6\% of the total). Most basins were located in the Nearctic region $(n=42)$. A low completeness value of $5 \%$ was assigned to all the river basins in which completeness values could not be computed ( $\mathrm{n}=70$; a $17 \%$ of total) due to the low number of database records and/or the lack of asymptotic tendencies.

All the diversity components were influenced by bias and by the unequal knowledge about different world basins. The diversity components significantly correlated to a greater or lesser degree with the completeness values derived from the accumulation functions (Pearson product-moment correlations oscillating from $r=-0.18$ in the case of LR to 0.77 for FRic; $\mathrm{p}<0.001$ in all cases). Thus, in addition to calculating WSBs, the dependence between diversity components and the survey effort carried out in each river basin was solved by performing a regression between the values of each diversity component and the completeness values obtained for the river basins. All these diversity metrics were firstly standardized to zero for means and one standard deviation to eliminate the effect of measurement scales. These regressions were adjusted to linear and quadratic functions in order to explore possible curvilinear relationships. A quadratic function is considered statistically significant when both linear and quadratic terms have a significance level of $\leq 1 \%$. The residuals of these regressions are thus un-correlated with the completeness values used as a surrogate for survey effort ( $r$ values are zero in all cases). Subsequently, the relationships between the different diversity components were examined using a simplified version of the procedure proposed by Stevens \& Tello [5] [6]. This procedure consisted of a principal component analysis (PCA) computed for the five diversity components (with a varimax normalized rotation) using the so generated orthogonal variables with eigenvalues higher than one as the main diversity dimensions. Of course, the values of diversity components and dimensions can be related with different types of explanatory variables (area, climate, historical, etc.). The objective in this study is not to examine the comparative relevance of different environmental variables on diversity differences, but to estimate the relationships among diversity components and the global distribution of the diversity dimensions.

\section{Results}

The raw data showed that functional richness was generally higher in the tropical regions of South America, Central America, Africa and Asia, but also, to a 
lesser extent, in North America and Europe (Figure 1). The functional richness of freshwater fish species had a geographical pattern partially similar to the pattern that had been observed for species richness ([38] Figure 1). Both variables were positively correlated both when the raw data was considered $(r=0.63 ; \mathrm{p}<$ $0.001)$, and when only WSBs were considered $(r=0.75 ; \mathrm{p}<0.001)$. The other diversity components had relatively more uniform geographical patterns (Figure $1)$.
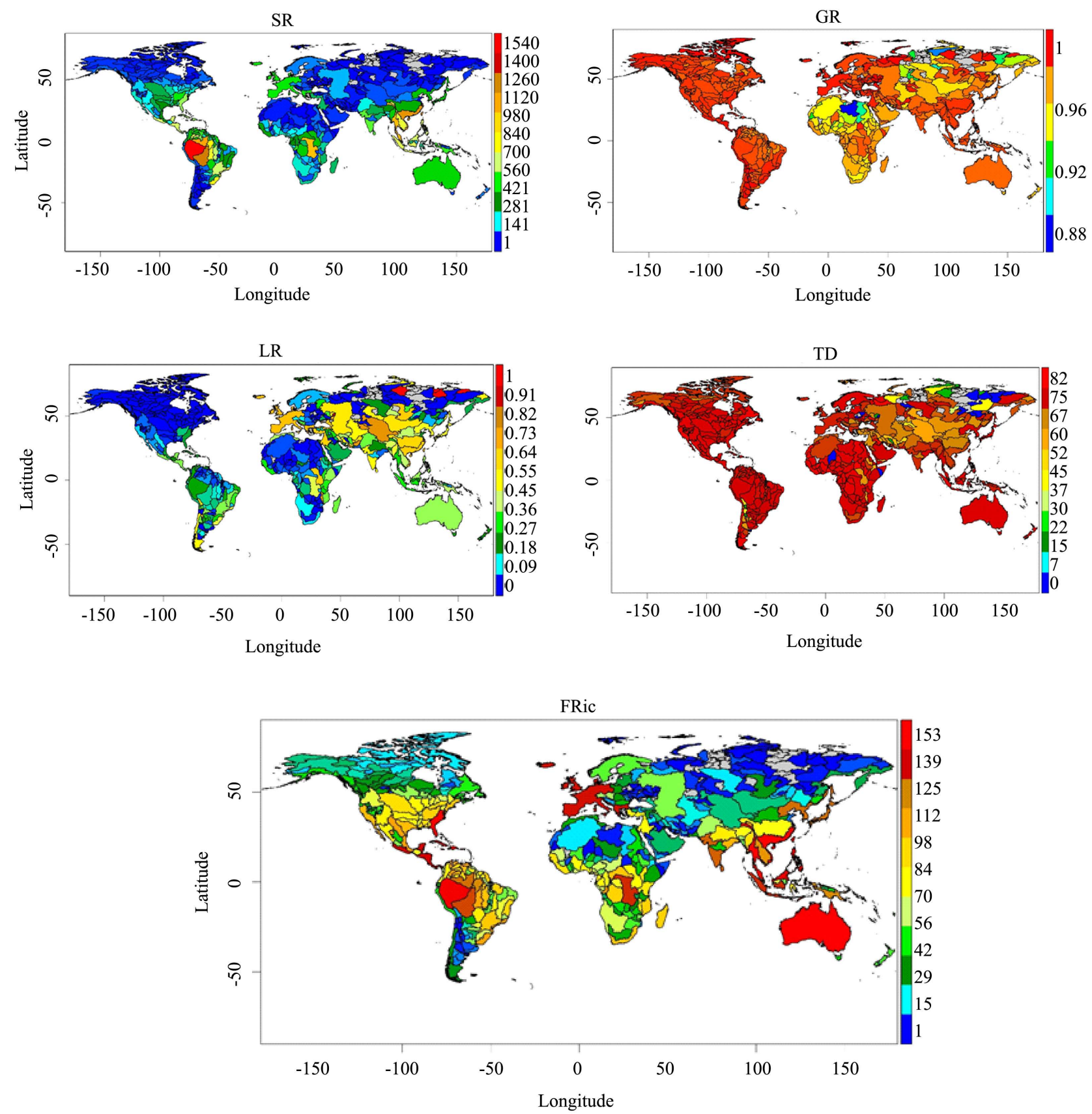

Figure 1. World patterns in the variation of the five considered diversity components emerging when the raw data is considered. $\mathrm{SR}=$ species richness, $\mathrm{GR}=$ geographic rarity, $\mathrm{LR}=$ Leroy rarity index, $\mathrm{TD}=$ taxonomic diversity, FRic = functional richness. Color bars represent the variations in the different components according to their own units of measure. 
Two diversity dimensions appear when the information coming from the 52 WSBs is considered. The PCA analysis indicated that these two dimensions accounted for $48.1 \%$ and $23.4 \%$ of the total variability in diversity components, respectively. The first dimension was positively related with SR, LR and FRic. These three components accounted for $88 \%, 77 \%$, and $62 \%$ of the variance of this factor, respectively (square of factor loadings). The second dimension is positively related with TD (67\% of variance) and GR (37\%). The results obtained with the WSBs did not match those observed when complete set of data was used in the analysis (Figure 2(a)). In this case, the two first PCA dimensions explained $40.8 \%$ and $27.3 \%$ of the total variability. The first dimension was positively related with SR, TD and FRic $(60 \%, 51 \%$ and $88 \%$ of variance, respectively), while the second dimension was positively related with the two rarity metrics GR (47\%) and LR (59\%).
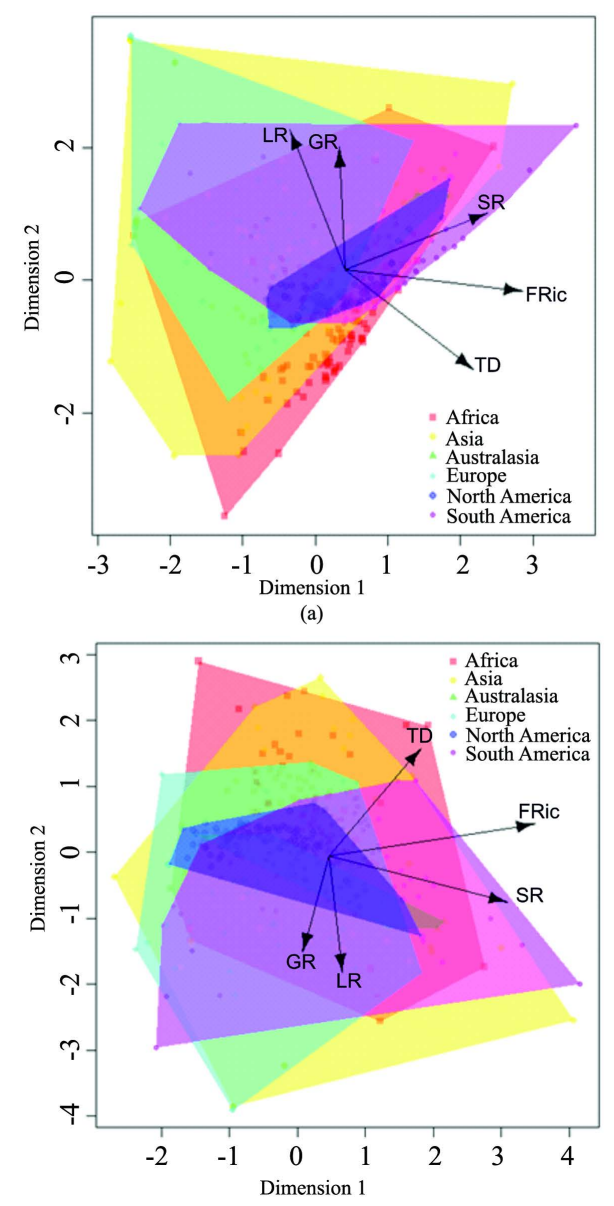

(b)

Figure 2. (a) Distribution of the raw diversity data regarding freshwater fishes in the space delimited by the two main dimensions of a Principal Component Analysis; (b) Distribution of the same diversity data when the effect of survey completeness on each diversity component was minimized by applying the residuals of a regression between the raw data and completeness values derived from accumulation curves. $S R=$ species richness, $\mathrm{GR}=$ geographic rarity, $\mathrm{LR}=$ Leroy rarity index, $\mathrm{TD}=$ taxonomic diversity, $\mathrm{FRic}=$ functional richness. Data are grouped by colour according to continent. 
Geographical patterns derived from the raw data were influenced by the unequal knowledge since all diversity components are positively correlated with completeness values and therefore, their variation could be explained by differences in the survey efforts carried out in each river basin (Table 1). The residuals of these regressions were rescaled to values of between 0 and 1 (corrected diversity components). A PCA analysis on these rescaled values again selected two diversity dimensions that could account for $34.3 \%$ and $30.4 \%$ of total variability in the diversity components, respectively (Figure 2(b)). As in the case of the WSB based analysis, the first dimension is positively correlated with SR and FRic ( $63 \%$ and $80 \%$ of total variance) but was uncorrelated with the two rarity components. The second dimension is negatively correlated with GR and LR ( $40 \%$ and $58 \%$ of variance), and positively correlated with TD ( $44 \%$ of total variance) (see Table 1). The geographical distribution of the so obtained dimensions (Figure 3) demonstrated that, some of the South American and South-Eastern Asian basins had the strongest species richness and functional diversity values (positive values of the dimension 1).
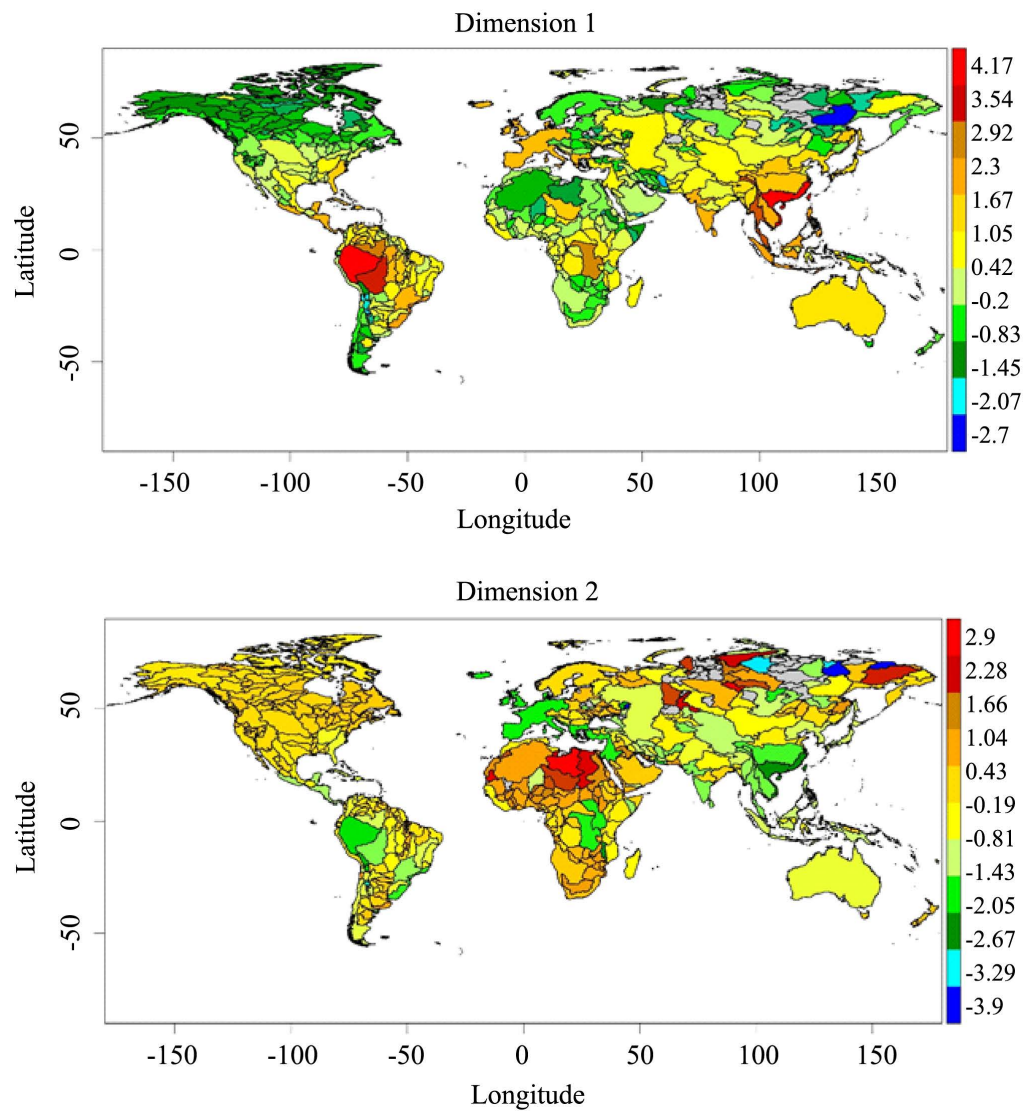

Figure 3. Global patterns in the variation of the two main PCA dimensions that summarize the data regarding the five diversity components. The raw data of each diversity component describing each river basin was regressed against the completeness values derived from the accumulation curves, and the resulting residuals managed in PCA analyses in order to minimize the effect of survey bias. Color bars represent the factors scores of each PCA dimension corresponding to each river basin. 
Table 1. Linear regressions between each diversity component and the completeness values for all the world river basins of level 2 (predictor variable). Completeness was calculated using accumulation curves that described the relationship between the accumulated number of species and the number of database records in each river basin. Regressions were adjusted using both linear and quadratic functions. DIM1 and DIM2 represent the factor loadings of the diversity components for the two first factors of a Principal Component Analysis carried out on the residuals of the relationships between each diversity component and completeness values. DIM1WSB and DIM2WSB were the factor loadings of each diversity component in a PCA analysis of the 52 river basins that were considered well-surveyed. $\mathrm{SR}=$ species richness, $\mathrm{GR}=$ geographic rarity, $\mathrm{LR}=$ Leroy rarity index, $\mathrm{TD}$ $=$ taxonomic diversity, FRic $=$ functional richness.

\begin{tabular}{ccccccccc}
\hline & $R^{2} \times 100$ & $F_{(2,409)}$ & $p$ & Relationship & DIM1 & DIM2 & DIM1 $1_{\text {WSB }}$ & DIM $2_{\text {WSB }}$ \\
\hline SR & 19.38 & 49.17 & $<0.0001$ & linear & 0.792 & -0.316 & 0.941 & 0.067 \\
GR & 3.25 & 6.88 & 0.001 & quadratic & 0.019 & -0.635 & -0.025 & 0.609 \\
LR & 5.49 & 11.88 & $<0.0001$ & quadratic & 0.169 & -0.765 & 0.881 & -0.164 \\
TD & 26.36 & 73.20 & $<0.0001$ & quadratic & 0.464 & 0.664 & 0.107 & 0.821 \\
FRic & 61.23 & 323.00 & $<0.0001$ & quadratic & 0.896 & 0.182 & 0.791 & 0.450 \\
\hline
\end{tabular}

Meanwhile, some of basins located in North Africa and in the north of the Palearctic region that were poor in species had higher taxonomic diversity (positive values in dimension 2). Rarity seemed to be high (negative values in the second dimension) in South America, South Eastern Asia, Central Africa and Europe (Figure 3). The frequency distributions of the corrected diversity components were different (Figure 4). Consequently, values equal to or higher than upper quartiles were selected and the corresponding basins qualified as the "most diverse". The geographical distributions of these "most diverse basins" allowed us to better assess the distribution of the above mentioned diversity dimensions and the relevance of the different diversity components (Figure 5). Both SR and FRic were found to be higher in eastern North America, tropical South America and Africa, Australasia, Easter Asia and Europe. However, TD was higher in the south of South America, the western part of the Nearctic region, North Africa, and across the Palearctic region. GR was higher in the northern part of North America, the southern part of South America, Europe and across the Palearctic region. LR was higher is the eastern part of Central Africa, Australasia, Asia, Europe and South America. Only in some in river basins of western South America $(\mathrm{n}=4)$, Europe and the Mediterranean region ( $\mathrm{n}$ $=3$ ), and South Eastern Asia $(n=5)$ was it possible to find high values of four diversity components (Figure 6).

\section{Discussion}

A primary goal of ecology and biogeography is to determine biodiversity patterns [60]. Biodiversity is generally described in terms of taxonomic entities. However, this approach has crucial limitations because it ignores the multidimensional character of diversity [5] [6] [7]. In this study, we aimed to surpass 

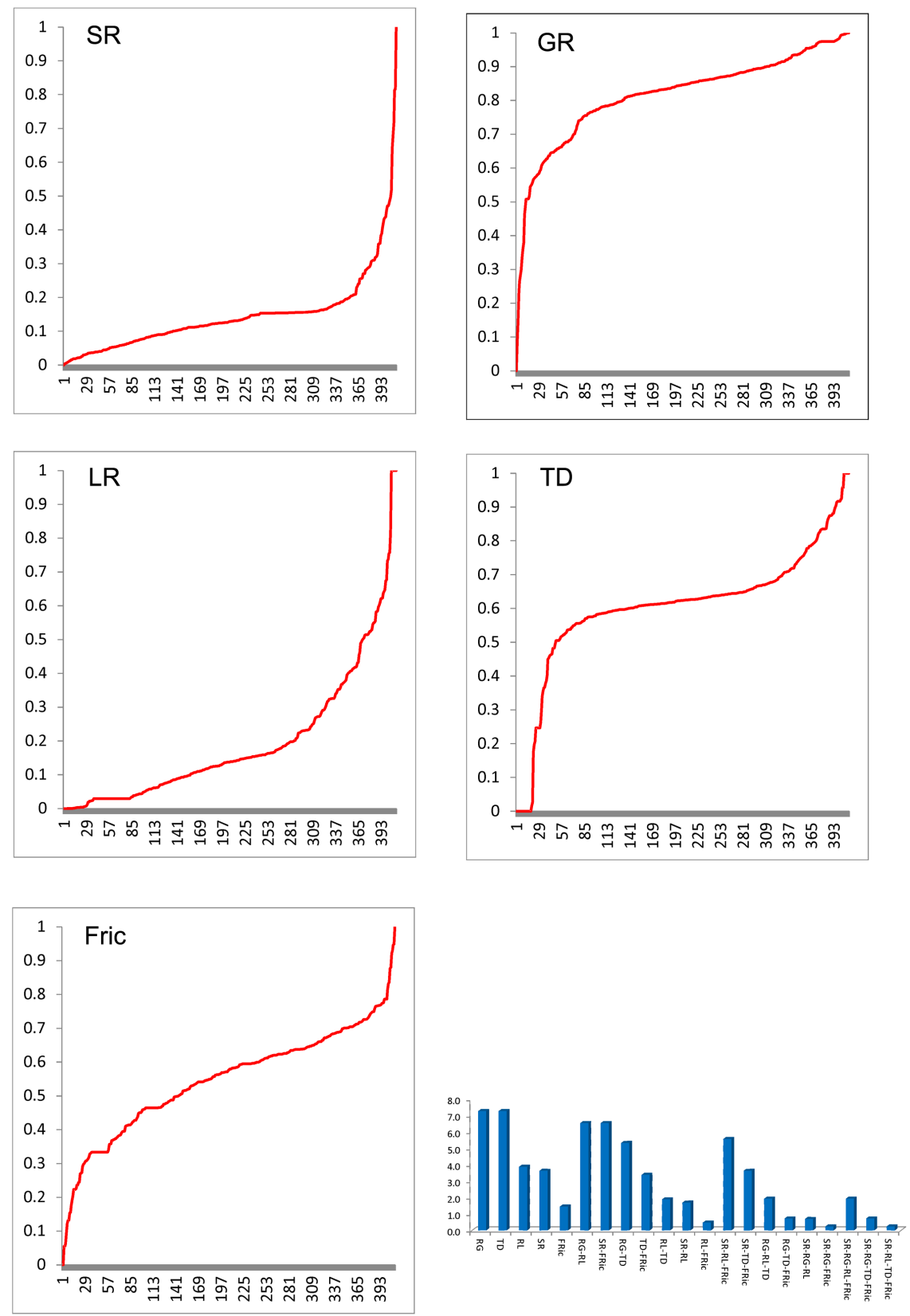

Figure 4. Frequency distributions of the corrected diversity components obtained after rescaling (between 0 and 1) the residuals of a regression between the raw data and completeness values derived from accumulation curves. SR = species richness, GR = geographic rarity, $\mathrm{LR}=$ Leroy rarity index, $\mathrm{TD}=$ taxonomic diversity, FRic $=$ functional richness. Bottom right histogram represents the percentage of world river basins selected by the different combinations of diversity components, when the continuous values representing each diversity component are transformed in binary ones by using as threshold those values equal or higher than upper quartiles.

the many limitations that stem from the biases and gaps in information about different diversity components [4] [37]. These shortcomings are evident in our analysis since only $13 \%$ of world river basins were defined as well-surveyed. Of these, $80 \%$ are located in the Nearctic region. What be done shed light on global 

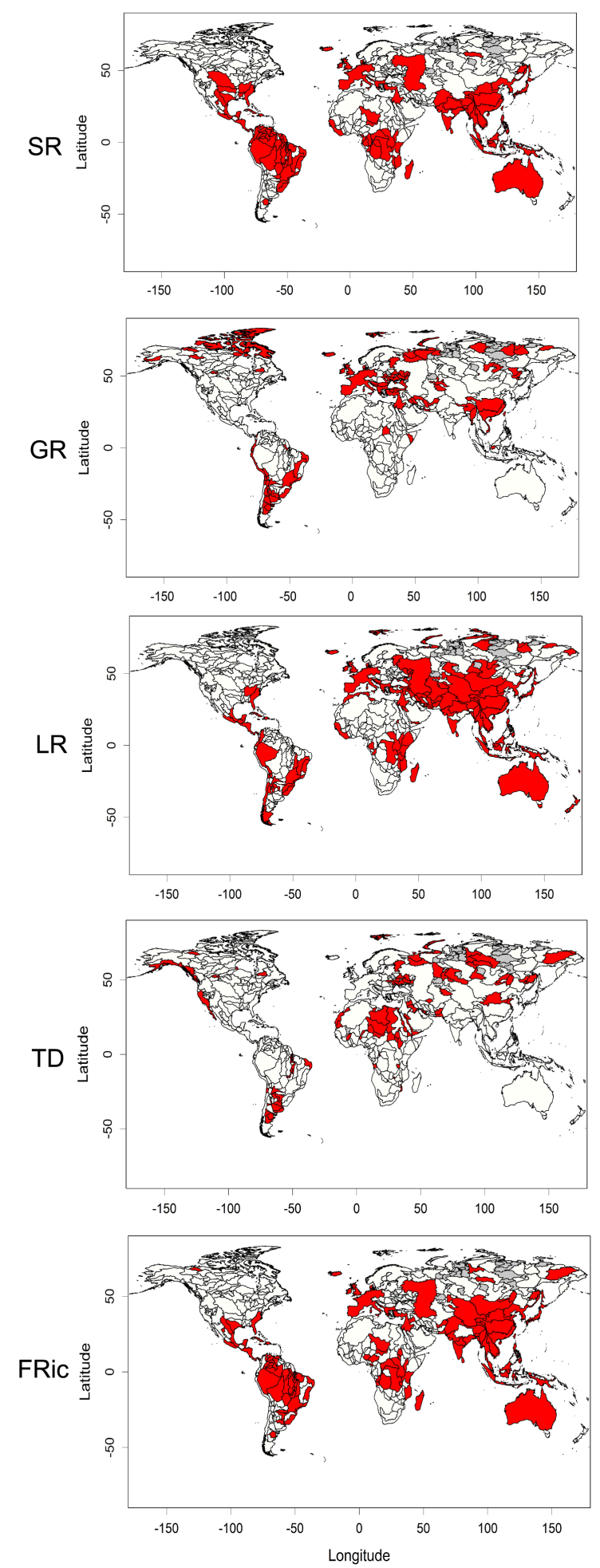

Figure 5. Global distribution of each diversity component. The raw data of each diversity component was regressed against the completeness values derived from the accumulation curves constructed for each river basin. Using as threshold those values equal or higher than the upper quartile, the so resulting residuals were rescaled to fit values of either 0 or 1. These values were then used to construct binary maps reflecting the "most diverse basins". SR = species richness, GR = geographic rarity, LR = Leroy rarity index, $T D=\operatorname{tax}-$ onomic diversity, FRic $=$ functional richness. 


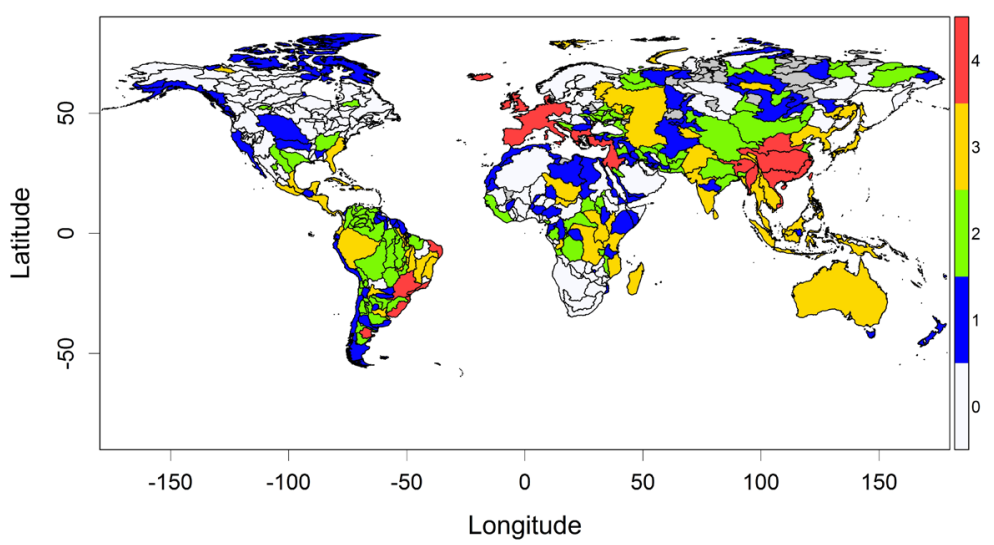

Figure 6. Level 2 global river basins that showed an increase in the diversity component values, as determined by overlaying the binary maps from Figure 5. Color bars represent the number diversity components qualified as "most diverse" for each river basin.

diversity patterns under these circumstances? Our approach has been to minimize the effects of these limitations by estimating the residuals of the relationship between each one of the diversity components and the completeness values derived from the accumulation functions. These corrected diversity components provide a less biased image about the global distribution of diversity in freshwater fishes. The confidence in these corrected diversity dimensions is based on the fact that they are fundamentally similar to those obtained from analysing well-surveyed river basins.

Kuczynski et al. [30] found a weak congruence between different diversity components in Europe. However, at a global scale our analyses show that the different diversity components representing the distribution of freshwater fishes in world river basins can adequately be summarized using only two main dimensions. The first diversity dimension reflects a gradient in species richness and functional diversity: these diversity components are higher in regions with a tropical or subtropical climate and lower in regions with arid, cold or cold-temperate conditions (see [61]). This gradient can be explained by taking into account the dominant effects of energy availability and habitat heterogeneity [17]. The second diversity dimension summarizes rarity and taxonomic diversity values that sometimes occur in some species rich basins such as in Easter South America, Europe or Eastern Asia. However, these basins are primarily located in species poor areas under arid, cold and cold-temperate conditions. Northern areas of the Holarctic region and southern South American basins covered by ice sheets during the Last Glacial Maximum could have propitiated the isolation and distinctiveness of the freshwater fishes found in these regions [62]. Similarly, the singularity of the Sino-Oriental or the arid African basins can be explained as a consequence of the isolation generated by the contraction of either ancient watercourses [63] or the uplift of the Tibetan plateau [64].

Studies on functional diversity have always shown a heterogeneous pattern with respect taxonomic groups and ecosystems. However, fish were usually not 
taken into account in these analyses. Freitas \& Mantorani [24] reviewed the works published from 1994 to 2014 and found that only $8 \%$ of the 621 functional diversity studies are about fish. Likewise, only $8 \%$ of these studies were performed on a global scale. Generally speaking, in these limited studies only small biogeographic areas were investigated and only ecomorphological aspects were considered [28] [65] [66] [67]. As far as we know, this is the first study in which the functional diversity of all species of freshwater fish known to date have been investigated in all their areas of geographic distribution. This analysis has shown that functional diversity and species richness are closely linked on a global scale. This relationship can vary depending on the chosen metrics [68], and the number of analysed traits [69]. However, the fact that this relationship between functional diversity and species richness can be observed in natural systems would indicate that a river basin with a higher number of species generally also has a higher number of occupied niches. Functional diversity influences ecosystem dynamics and stability [70]. Therefore, the association observed between these two diversity components among world freshwater fish would suggest that ecosystem functions increase with the number of fish species found in river basins, but also that a decrease in species richness might involve a loss of functionality.

\section{Conclusion}

In this study, we aim to surpass the biases and gaps in the distributional information on world freshwater fishes taking into account the multidimensional character of diversity. The provisional character of this faunistic data is evident because just one world basin in seven would have a reliable inventory, most part of them located in the Nearctic region. Considering completeness calculations, we propose here to estimate corrected diversity components able to provide a less biased image. This approach seems to generate reliable patterns when they are compared with those coming from the analysis of well-surveyed basins. In the light of this work, two diversity dimensions seem to be enough to offer a consistent picture on the geographical patterns of world freshwater fishes. One dimension is related with the tropical-temperate latitudinal gradient in species richness and functional diversity, and another associated with the higher rarity and taxonomic diversity that host some species poor areas located under arid, cold and cold-temperate conditions.

\section{Acknowledgements}

We are indebted to all the organizations, institutions and people whose efforts have made it possible to compile the valuable biological data that now are freely available.

\section{Conflicts of Interest}

The authors declare no conflicts of interest regarding the publication of this manuscript. 


\section{Data Availability Statement}

All the primary data used in this study are freely available in the IPez1.4 website (http://www.ipez.es). Data sources include GBIF derived dataset filtered export of GBIF occurrence data https://doi.org/10.15468/dd.fp89mv. A detailed description of the data sources, the considered species, the states of each biological trait assigned to each species, and the values of the diversity components, the slopes, completeness, and the ratios of the number of species to records for each level 2 river basin are available upon request.

\section{References}

[1] Scott, J.M., Davis, B., Csuti, R., et al. (1993) Gap Analysis: A Geographic Approach to Protection of Biological Diversity. Wildlife Monographs, 123, 3-41.

[2] Meynard, C.N., Devictor, V., Mouillot, D., et al. (2011) Beyond Taxonomic Diversity Patterns: How Do Alpha, Beta and Gamma Components of Bird Functional and Phylogenetic Diversity Respond to Environmental Gradient across France? Global Ecology and Biogeography, 20, 893-903. https://doi.org/10.1111/j.1466-8238.2010.00647.x

[3] Conroy, M.J. and Noon, B.R. (1996) Mapping of Species Richness for Conservation of Biological Diversity: Conceptual and Methodological Issues. Ecological Applications, 6, 763-773. https://doi.org/10.2307/2269481

[4] Hortal, J., de Bello, F., Diniz-Filho, J.A.F., et al. (2015) Seven Shortfalls That Beset Large-Scale Knowledge of Biodiversity. Annual Review of Ecology, Evolution, and Systematics, 46, 523-549. https://doi.org/10.1146/annurev-ecolsys-112414-054400

[5] Stevens, R.D. and Tello, J.S. (2014) On the Measurement of Dimensionality of Biodiversity. Global Ecology and Biogeography, 23, 1115-1125.

https://doi.org/10.1111/geb.12192

[6] Stevens, R.D. and Tello, J.S. (2018) A Latitudinal Gradient in Dimensionality of Biodiversity. Ecography, 41, 2016-2026. https://doi.org/10.1111/ecog.03654

[7] Naeem, S., Prager, C., Weeks, B., et al. (2016) Biodiversity as a Multidimensional Construct: A Review, Framework and Case Study of Herbivory's Impact on Plant Biodiversity. Proceedings Royal Society B, 283, Article ID: 20153005.

https://doi.org/10.1098/rspb.2015.3005

[8] Flynn, D.F.B., Mirotchnick, N., Jain, M., et al. (2011) Functional and Phylogenetic Diversity as Predictors of Biodiversity-Ecosystem Function Relationships. Ecology, 92, 1573-1581. https://doi.org/10.1890/10-1245.1

[9] Cadotte, M.W., Cavender-Bares, J., Tilman, D., et al. (2009) Using Phylogenetic, Functional and Trait Diversity to Understand Patterns of Plant Community Productivity. PLoS ONE, 4, e5695. https://doi.org/10.1371/journal.pone.0005695

[10] Le Bagousse-Pingueta, Y., Soliveres, S., Grossa, N., et al. (2019) Phylogenetic, Functional, and Taxonomic Richness Have Both Positive and Negative Effects on Ecosystem Multifunctionality. Proceedings of the National Academy of Sciences of the United States of America, 116, 8419-8424.

https://doi.org/10.1073/pnas.1815727116

[11] Oberdorff, T., Guégan, J.F. and Hugueny, B. (1995) Global Scale Patterns in Freshwater Fish Species Diversity. Ecography, 18, 345-352.

https://doi.org/10.1111/j.1600-0587.1995.tb00137.x

[12] Oberdorff, T., Lek, S. and Guégan, J.F. (1999) Patterns of Endemism in Riverine 
Fish of the Northern Hemisphere. Ecology Letters, 2, 75-81. https://doi.org/10.1046/j.1461-0248.1999.t01-2-22051.x

[13] Tedesco, P.A., Leprieur, F., Hugueny, B., et al. (2012) Patterns and Processes of Global Riverine Fish Endemism. Global Ecology and Biogeography, 21, 977-987. https://doi.org/10.1111/j.1466-8238.2011.00749.x

[14] Leprieur, F., Tedesco, P.A., Hugueny, B., et al. (2011) Partitioning Global Patterns of Freshwater Fish Beta Diversity Reveals Contrasting Signatures of Past Climate Changes. Ecology Letters, 14, 325-334. https://doi.org/10.1111/j.1461-0248.2011.01589.x

[15] Casties, I. and Briski, E. (2019) Life History Traits of Aquatic Non-Indigenous Species: Freshwater vs. Marine Habitats. Aquatic Invasions, 14, 566-581.

https://doi.org/10.3391/ai.2019.14.4.01

[16] Villéger, S, Grenouillet, G. and Brosse, S. (2014) Functional Homogenization Exceeds Taxonomic Homogenization among European Fish Assemblages. Global Ecology and Biogeography, 23, 1450-1460. https://doi.org/10.1111/geb.12226

[17] Guégan, J.F., Lek, S. and Oberdorff, T. (1998) Energy Availability and Habitat Heterogeneity Predict Global Riverine Fish Diversity. Nature, 391, 382-384.

https://doi.org/10.1038/34899

[18] Hugueny, B., Oberdorff, T. and Tedesco, P.A. (2010) Community Ecology of River Fishes: A Large Scale Perspective. In: Jackson, D. and Gido, K., Eds., Community Ecology of Stream Fishes: Concepts, Approaches and Techniques, American Fisheries Society Symposium, Bethesda, 29-62.

[19] Strecker, A.L., Olden, J.D., Whittier, J.B., et al. (2011) Defining Conservation Priorities for Freshwater Fishes According to Taxonomic, Functional, and Phylogenetic Diversity. Ecological Applications, 21, 3002-3013. https://doi.org/10.1890/11-0599.1

[20] Rolls, R.J., Heino, J., Ryder, D.S., et al. (2018) Scaling Biodiversity Responses to Hydrological Regimes. Biological Review, 93, 971-995.

https://doi.org/10.1111/brv.12381

[21] de Carvalho, R.A. and Tejerina-Garro, F.L. (2015) Relationships between Taxonomic and Functional Components of Diversity: Implications for Conservation of Tropical Freshwater Fishes. Freshwater Biology, 60, 1854-1862. https://doi.org/10.1111/fwb.12616

[22] Decker, E., Linke, S., Hermoso, V., et al. (2017) Incorporating Ecological Functions in Conservation Decision Making. Ecology and Evolution, 7, 8273-8281. https://doi.org/10.1002/ece3.3353

[23] Naeem, S., Duffy, J.E. and Zavaleta, E. (2012) The Functions of Biological Diversity in an Age of Extinction. Science, 336, 1401-1406. https://doi.org/10.1126/science.1215855

[24] Freitas, J.R. and Mantovani, W. (2018) An Overview of the Applicability of Functional Diversity in Biological Conservation. Brazilian Journal of Biology, 78, 517-524. https://doi.org/10.1590/1519-6984.09416

[25] Winemiller, K.O. (1991) Ecomorphological Diversification of Freshwater Fish Assemblages from Two Biotic Regions. Ecological Monographs, 61, 343-365. https://doi.org/10.2307/2937046

[26] Pont, D., Hugueny, B., Beier, U., et al. (2006) Assessing River Biotic Condition at a Continental Scale: A European Approach Using Functional Metrics and Fish Assemblages. Journal of Applied Ecology, 43, 70-80. https://doi.org/10.1111/j.1365-2664.2005.01126.x 
[27] Comte, L., Cucherousset, J., Boulêtvean, S., et al. (2016) Resource Partitioning and Functional Diversity of Worldwide Freshwater Fish Communities. Ecosphere, 7, e01356. https://doi.org/10.1002/ecs2.1356

[28] Toussaint, A., Chapin, N., Brosse, S., et al. (2016) Global Functional Diversity of Freshwater Fish Is Concentrated in the Neotropics While Functional Vulnerability Is Widespread. Scientific Reports, 6, 122-125. https://doi.org/10.1038/srep22125

[29] Kang, B., Huang, X., Yan, Y., et al. (2018) Continental-Scale Analysis of Taxonomic and Functional Fish Diversity in the Yangtze River. Global Ecology and Conservation, 15, e00442. https://doi.org/10.1016/j.gecco.2018.e00442

[30] Kuczynski, L., Cote, J., Toussaint, A., et al. (2018) Spatial Mismatch in Morphological, Ecological and Phylogenetic Diversity in Historical and Contemporary European Freshwater Fish Faunas. Ecography, 41, 1665-1674.

https://doi.org/10.1111/ecog.03611

[31] Lamothe, K.A., Alofs, K.M., Jackson, D., et al. (2018) Functional Diversity and Redundancy of Freshwater Fish Communities across Biogeographic and Environmental Gradients. Diversity and Distributions, 24, 1612-1626.

https://doi.org/10.1111/ddi.12812

[32] Lechêne, A., Lobry, J., Boët, P., et al. (2018) Change in Fish Functional Diversity and Assembly in the Course of Tidal Marsh Restoration. PLOS ONE, 13, e0209025. https://doi.org/10.1371/journal.pone.0209025

[33] Toussaint, A., Chapin, N., Beauchard, O., et al. (2018) Non-Natives Species Led to Marked Shifts in Functional Diversity of the World Freshwater Fish Faunas. Ecology Letters, 21, 1649-1659. https://doi.org/10.1111/ele.13141

[34] Dumay, O., Tari, P.S., Tomasini, J.A., et al. (2004) Functional Groups of Lagoon Fish Species in Languedoc Roussillon, Southern France. Journal of Fish Biology, 64, 970-983. https://doi.org/10.1111/j.1095-8649.2004.00365.x

[35] Stuart-Smith, R.D., Bates, A.E., Lefcheck, J.S., et al. (2013) Integrating Abundance and Functional Traits Reveals New Global Hotspots of Fish Diversity. Nature, 501, 539-542. https://doi.org/10.1038/nature12529

[36] Lefcheck, J.S., Innes-Gold, A.A., Brandl, S.J., et al. (2019) Tropical Fish Diversity Enhances Coral Reef Functioning across Multiple Scales. Sciences Advances, 5, eaav6420. https://doi.org/10.1126/sciadv.aav6420

[37] Pelayo-Villamil, P., Guisande, C., Manjarrés-Hernández, A., et al. (2018) Completeness of National Freshwater Fish Species Inventories around the World. Biodiversity and Conservation, 27, 3807-3817. https://doi.org/10.1007/s10531-018-1630-y

[38] Pelayo-Villamil, P., Guisande, C., Vari, R.P., et al. (2015) Global Diversity Patterns of Freshwater Fishes-Potential Victims of Their Own Success. Diversity and Distributions, 21, 345-356. https://doi.org/10.1111/ddi.12271

[39] Pelayo-Villamil, P., Guisande, C., González-Vilas, L., et al. (2012) ModestR: Una herramienta informática para el estudio de los ecosistemas acuáticos de Colombia. Actualidades Biológicas, 34, 225-239.

[40] García-Roselló, E., Guisande, C., González-Dacosta, J., et al. (2013) ModestR: A Software Tool for Managing and Analysing Species Distribution Map Databases. Ecography, 36,102-1207. https://doi.org/10.1111/j.1600-0587.2013.00374.x

[41] García-Roselló, E., Guisande, C., Heine, J., et al. (2014) Using ModestR to Download, Import and Clean Species Distribution Records. Methods in Ecology and Evolution, 5, 703-713. https://doi.org/10.1111/2041-210X.12209 
[42] García-Roselló, E., Guisande, C., Manjarrés-Hernández, A., et al. (2015) Can We Derive Macroecological Patterns from Primary GBIF Data? Global Ecology and Biogeography, 24, 335-347. https://doi.org/10.1111/geb.12260

[43] Guisande, C., Manjarrés-Hernández, A., Pelayo-Villamil, P., et al. (2010) IPez: An Expert System for the Taxonomic Identification of Fishes Based on Machine Learning Techniques. [Fisheries Research, 102, 240-247. https://doi.org/10.1016/j.fishres.2009.12.003

[44] Verdin, K.L. and Verdin, J.P. (1999) A Topological System for Delineation and Codification of Earth's River Basins. Journal of Hydrology, 218, 1-12. https://doi.org/10.1016/S0022-1694(99)00011-6

[45] Verdin, K.L. and Greenlee, S.K. (2016) HYDRO1k Documentation. US Geological Survey [Online].

http://webgis.wr.usgs.gov/globalgis/metadata_qr/metadata/hydro1k.htm

[46] González-Vilas, L., Guisande, C., Vari, R.P., et al. (2016) Geospatial Data of Freshwater Habitats for Macroecological Studies: An Example with Freshwater Fishes. International Journal of Geographical Information Science, 30, 126-141. https://doi.org/10.1080/13658816.2015.1072629

[47] Manjarrés-Hernández, A.M., Guisande, C., García-Roselló, E., et al. (2018) A Procedure to Assess the Spatial Variability in the Importance of Abiotic Factors Affecting Distributions: The Case of World Freshwater Fishes. Current Zoology, 64, 549-557. https://doi.org/10.1093/cz/zox063

[48] Guisande, C, Heine, J., García-Roselló, E., et al. (2017) DER: An Algorithm for Comparing Species Diversity between Assemblages. Ecological Indicators, 81, 41-46. https://doi.org/10.1016/j.ecolind.2017.05.049

[49] Guisande C. (2018) Ecological Indicators. R Package Version. 1.4. https://cran.r-project.org/web/packages/EcoIndR

[50] R Development Core Team (2020) A Language and Environment for Statistical Computing. R Foundation for Statistical Computing, Vienna.

[51] Gaston, K.J. (1994) Rarity. Chapman and Hall, London. https://doi.org/10.1007/978-94-011-0701-3

[52] Leroy, B., Petillon, J., Gallon, R., et al. (2012) Improving Occurrence-Based Rarity Metrics in Conservation Studies by Including Multiple Rarity Cut-Off Points. Insect Conservation and Diversity, 5, 159-168. https://doi.org/10.1111/j.1752-4598.2011.00148.x

[53] Leroy, B., Canard, A. and Ysnel, F. (2013) Integrating Multiple Scales in Rarity Assessments of Invertebrate Taxa. Diversity and Distribution, 19, 794-803. https://doi.org/10.1111/ddi.12040

[54] Warwick, R. and Clarke, K.R. (2001) Practical Measures of Marine Biodiversity Based on Relatedness of Species. Oceanography Marine Biology, 39, 207-231.

[55] Villéger, S., Mason, N.W.H. and Mouillot, D. (2008) New Multidimensional Functional Diversity Indices for a Multifaceted Framework in Functional Ecology. Ecology, 89, 2290-2301. https://doi.org/10.1890/07-1206.1

[56] Buisson, L., Grenouillet, G., Villéger, S., et al. (2013) Toward a Loss of Functional Diversity in Stream Fish Assemblages under Climate Change. Global Change Biology, 19, 387-400. https://doi.org/10.1111/gcb.12056

[57] Guisande, C., Heine, J., González-Dacosta, J., et al. (2014) RWizard Software. University of Vigo, Vigo. http://www.ipez.es/RWizard

[58] Lobo, J.M., Hortal, J., Yela, J.L., et al. (2018) KnowBR: An Application to Map the 
Geographical Variation of Survey Effort and Identify Well-Surveyed Areas from Biodiversity Databases. Ecological Indicators, 91, 241-248. https://doi.org/10.1016/j.ecolind.2018.03.077

[59] Guisande, C. and Lobo, J.M. (2019) Discriminating Well Surveyed Spatial Units from Exhaustive Biodiversity Databases. R Package Version 2.0. http://cran.r-project.org/web/packages/KnowBR

[60] Carmona, C., de Bello, F., Mason, N.W.H., et al. (2016) Traits without Borders: Integrating Functional Diversity across Scales. Trends in Ecology and Evolution, 31, 382-394. https://doi.org/10.1016/j.tree.2016.02.003

[61] Leroy, B., Dias, M.S., Giraud, E., et al. (2019) Global Biogeographical Regions of Freshwater Fish Species. Journal of Biogeography, 46, 2407-2419. https://doi.org/10.1111/jbi.13674

[62] Dias, M.S., Oberdorff, T., Hugueny, B., et al. (2014) Global Imprint of Historical Connectivity on Freshwater Fish Biodiversity. Ecology Letters, 17, 1130-1140. https://doi.org/10.1111/ele.12319

[63] Drake, N.A., Blench, R.M., Armitage, S.J., et al. (2011) Ancient Watercourses and Biogeography of the Sahara Explain the Peopling of the Desert. Proceedings of the National Academy of Sciences of the United States of America, 108, 458-462. https://doi.org/10.1073/pnas.1012231108

[64] Xing, Y., Zhang, C., Fan, E., et al. (2015) Freshwater Fishes of China: Species Richness, Endemism, Threatened Species and Conservation. Diversity and Distributions, 22, 358-370. https://doi.org/10.1111/ddi.12399

[65] Halpern, B.S. and Floeter, S.R. (2008) Functional Diversity Responses to Changing Species Richness in Reef Fish Communities. Marine Ecology Progress Series, 364, 147-156. https://doi.org/10.3354/meps07553

[66] Villéger, S., Ramos Miranda, J., Flores Hernández, D., et al. (2010) Contrasting Changes in Taxonomic vs. Functional Diversity of Tropical Fish Communities after Habitat Degradation. Ecological Applications, 20, 1512-1522.

https://doi.org/10.1890/09-1310.1

[67] Winemiller, K.O., Fitzgerald, D.B., Bower, L.M., et al. (2015) Functional Traits, Convergent Evolution and Periodic Tables of Niches. Ecology Letters, 18, 737-751. https://doi.org/10.1111/ele.12462

[68] Schmera, D., Heino, J., Podani, J., et al. (2017) Functional Diversity: A Review of Methodology and Current Knowledge in Freshwater Macroinvertebrate Research. Hydrobiologia, 787, 27-44. https://doi.org/10.1007/s10750-016-2974-5

[69] Guillemont, N., Kulbicki, M., Chabanet, P., et al. (2011) Functional Redundancy Patterns Reveal Non-Random Assembly Rules in a Species-Rich Marine Assembly. PLoS ONE, 6, 226375. https://doi.org/10.1371/journal.pone.0026735

[70] Tilman, D. (1999) The Ecological Consequences of Changes in Biodiversity: A Search for General Principles. Ecology, 80, 1455-1474.

https://doi.org/10.2307/176540 